\title{
Les médecins ne sont-ils que des empêcheurs?
}

A en croire Santésuisse, certains de ses principaux porte-parole et les milieux politiques quasiment unanimes, il est totalement illusoire de compter eux et leurs organisations professionnelles pour trouver des solutions effectives à l'augmentation incessantes des coûts qui ronge le système suisse de santé depuis plusieurs années. Les médecins ne font que s'accrocher contre vents et marée à des privilèges aussi dépassés qu'injustifiés. Pour preuve les négociations sur TARMED ont été interminables et ne sont d'ailleurs pas encore absolument entièrement terminées. Elles se poursuivent dans un climat de contestations explosives. L'ordonnance sur la clause du besoin a déclenché une véritable montée aux barricades. Et la révision de la LAMal se heurte à des manœuvres de blocages et verrouillages multiples avec menace de referendum à la clé.

Il est vrai que les responsables de la FMH et des sociétés cantonales ont été jusqu'à présent surtout confrontés à des débats internes difficiles en rapport avec TARMED et les multiples tentatives de mettre notre profession sous la tutelle des caisses-maladie. Ils se sont rarement exprimés ouvertement en public. Pourtant les mises en garde bien intentionnées adressées aux partenaires et aux politiques concernant les difficultés techniques d'application des mesures envisagées pour maîtriser les coûts de la santé n'ont été interprétées que comme des opérations de diversion. Comment d'ailleurs attribuer la moindre crédibilité à ces propos? Qu'on le veuille ou non et quoi qu'on dise, la situation de l'ensemble du corps médical est extrêmement confortable, et somme toute assez peu éloignée de celle de quelques numismates notoires dont les revenus hors normes et les scandales périodiques font la une de la Press People.

Cette fois-ci la discussion change manifestement de ton. La Société médicale de la Suisse romande entend exprimer son sentiment dans ce débat systématiquement biaisé. Ce sont des présidents de sociétés cantonales qui tentent bon gré mal gré de calmer l'exaspération souvent légitime de leurs troupes face aux menaces incessantes qui déstabilisent notre profession. Ils sont tous des généralistes sauf l'un d'eux qui est gynécologue. Ils pratiquent plutôt en périphérie et n'appartiennent pas à l'establishment universitaire. Qui mieux que ces présidents profondément implantés dans le terrain, celui de l'ensemble de leurs pairs et celui de leurs patients, pour faire part de manière concrète des préoccupations des uns et des autres, pour débloquer un dialogue de sourds conduisant à l'impasse, et formuler des propositions sans nécessairement vouloir défendre des privilèges, mais seulement une vision de l'avenir de la médecine qui croit encore à un certain nombre de valeurs? Elles témoignent d'une volonté forte, d'une volonté sincère, qui va au-delà des procès d'intention et doit être prise très au sérieux.

Dr Yves Guisan, Vice-président FMH, Conseiller national 


\section{Sind Ärzte nichts als Verhinderer?}

Wenn man der santésuisse, einigen ihrer wichtigsten Pressesprecher und den fast einstimmigen Voten der Politiker glauben will, ist es völlig illusorisch, auf die Ärzte und ihre Berufsorganisationen zu zählen, um wirksame Lösungen für die seit Jahren wachsenden und das Schweizer Gesundheitswesen aufzehrenden Kosten zu finden: Die Ärzte klammern sich verbissen an ihre ebenso überholten wie ungerechtfertigten Privilegien. Als Beweis dafür könne man auf die TARMED-Verhandlungen verweisen, die sich endlos hingezogen haben und auch heute noch nicht ganz abgeschlossen sind. Die Verhandlungen finden überdies in einer explosiven Atmosphäre des Protestes statt. Die Verordnung über die Bedürfnisklausel hat einen regelrechten Aufstand provoziert. Auch die KVG-Revision stösst auf Widerstand und Verhinderungsversuche aller Art, dies vor dem Hintergrund einer latenten Referendumsdrohung.

Tatsächlich waren die Verantwortlichen der FMH und der kantonalen Ärztegesellschaften bisher vor allem mit schwierigen internen Auseinandersetzungen zu TARMED und den zahlreichen Versuchen, unseren Berufsstand unter die Bevormundung der Krankenkassen zu stellen, beschäftigt. Sie haben sich bisher auch kaum in der Öffentlichkeit geäussert. Allerdings wurden wohlgemeinte Warnungen an die Adresse der Partner und Politiker über technische Schwierigkeiten bei der Umsetzung vorgesehener Massnahmen zur Dämpfung der Gesundheitskosten lediglich als Diversionsmanöver interpretiert. Wie könne man diesen Äusserungen die geringste Glaubwürdigkeit beimessen? $\mathrm{Ob}$ man es wolle oder nicht, und was auch immer gesagt werden könne: die Situation der gesamten Ärzteschaft sei überaus komfortabel und alles in allem nicht weit entfernt von jenen bekannten Numismatikern, deren aussergewöhnlich hohe Einkommen und Skandale die Schlagzeilen der Boulevardpresse bestimmen.

Nun hat sich die Tonalität der Diskussion ganz offensichtlich gewandelt. Die «Société Médicale de la Suisse Romande» (SMSR) hat beschlossen, ihren Standpunkt in diese sonst systematisch verzerrte Diskussion einzubringen. Es sind Präsidenten der kantonalen Ärztegesellschaften, die wohl oder übel versuchen, die häufig zu Recht über die unaufhörlichen und unseren Berufsstand destabilisierenden Drohungen aufgebrachten Kollegen zu beschwichtigen. Alle Präsidenten sind Allgemeinpraktiker, ausser einem, der Gynäkologe ist. Sie praktizieren meist ausserhalb der grossen Zentren und gehören nicht dem universitären Establishment an. Wer könnte besser als diese Präsidenten, die mit den Sorgen und Nöten all ihrer Kollegen und Patienten bestens vertraut sind, der da und dort anzutreffenden Besorgnis konkreten Ausdruck verleihen, um den aneinander vorbei und in die Sackgasse führenden Dialog wieder in Gang $\mathrm{zu}$ bringen und Vorschläge $\mathrm{zu}$ machen, ohne dabei nur Privilegien verteidigen zu wollen, sondern um einfach eine Sicht der Zukunft der Medizin zu vermitteln, die noch an gewisse Werte glaubt?

Diese Vorschläge zeugen von starkem Willen, von ehrlichem Willen, der von Unterstellungen Abstand nimmt und sehr ernst genommen werden muss.

Dr. med. Yves Guisan, Vize-Präsident der FMH, Nationalrat 